This is the peer reviewed version of the following article: "Martínez, A.B., Salazar, A., León, N., Illescas, S., and Rodríguez, J. (2016) Influence of the notch-sharpening technique on styrene-acrylonitrile fracture behavior. Journal of Applied Polymer Science, Vol. 133, Issue 32." which has been published in final form at [DOI: 10.1002/app.43775]. This article may be used for non-commercial purposes in accordance with Wiley Terms and Conditions for Self-Archiving." 


\title{
Influence of the notch-sharpening technique on styrene- acrylonitrile fracture behavior
}

\author{
A. B. Martínez ${ }^{1}$, A. Salazar ${ }^{2}$, N. León ${ }^{1}$, S. Illescas $^{1}$, J. Rodríguez ${ }^{2}$ \\ ${ }^{1}$ Centre Català del Plàstic, Departament de Ciència dels Materials i Enginyeria Metal· lúrgica, Universitat \\ Politècnica de Catalunya, C/ Colom 114, 08222, Terrassa, Spain \\ ${ }^{2}$ Grupo de Durabilidad e I ntegridad Mecánica de Materiales Estructurales, Universidad Rey J uan Carlos, C/ \\ Tulipán, s/n 28933, Móstoles \\ Madrid, Spain \\ Correspondenceto: A. Salazar (E-mail: alicia.salazar@urjc.es)
}

\begin{abstract}
The Centre Català del Plâstic and Universidad Rey Juan Carlos laboratories joined forces to investigate the effect of the notch-sharpening technique on the fracture parameters of styrene-acrylonitrile. Contact notchsharpening techniques, such as razor tapping, razor sliding, and razor broaching, and a noncontact procedure, femtolaser, were analyzed. The fracture values of the samples with notches sharpened via contact techniques were divided into two groups: one with pop-in and the other with no pop-in in the load-displacement records; this resulted in the lowest and highest fracture toughnesses, respectively. The fracture parameters of the specimens with notches sharpened via a femtolaser were between those of the samples with notches sharpened via contact procedures in which pop-in occurred and those in which it did not. To explain these results, the crack front of the nontested specimens after sharpening was investigated in depth, we identified the type of damage and measured its size and the crack tip radii. The morphology of the crack front was related to the fractographic study.
\end{abstract}

KEYWORDS: mechanical properties; polystyrene; properties and characterization; thermoplastics

\section{INTRODUCTION}

The fracture testing of polymers still has some unsolved issues, among which notch sharpening has recently gained the attention of the scientific community. The fracture toughness testing of materials requires that the body contains a sharp crack, and the standard procedure for the notch sharpening of polymers differs from that of metals. Polymers are soft compared to metals, so the fatigue notch sharpening of the former is considered to be a time-consuming and ineffective technique because the testing frequency must be kept very low $(<4 \mathrm{~Hz}$ in some plastics) to prevent hysteretic heating and because cycling loading can promote unstable fatigue crack growth $^{1}$. For all of these reasons, widespread procedures for the notch sharpening of polymers are contact methods based on the use of razor blades, as described by both European Structural Integrity Society ${ }^{1-6}$ and American Society for Testing and Materials ${ }^{-7}$ standards and protocols for the fracture testing of polymers.

Some works have highlighted the fact that the lack of repeatability and reproducibility in the fracture results of polymers can be due to the poor quality of the sharpened notches introduced by traditional contact notch sharpening. ${ }^{10-22}$ Peres et al. ${ }^{10}$ and de Souza et al..$^{11}$ investigated the effect of two contact techniques, razor tapping and razor pressing, on the fracture toughness obtained under a linear elastic fracture mechanics (LEFM) approach of a medium-density polyethylene and a poly(methyl methacrylate) PMMA resin, respectively. The fracture toughness values presented less scatter when the razor pressing technique was used in polyethylene and when the tapping procedure was used for the PMMA resin. In this very research line, Agnelli and Horsfall ${ }^{12}$ concluded that the notching technique was a key factor in controlling the scatter of the high-rate fracture toughness values of different polymers, such as poly(vinyl chloride) or PMMA resin. However, with no doubt, these authors ${ }^{13-21}$ have carried out extensive work on the influence of notch-sharpening procedures on fracture parameters evaluated under different approaches and on different types of polymers, including semicrystalline thermoplastics (ethylene propylene block copolymers ${ }^{13-17,21}$ ), amorphous thermoplastics [polycarbonate ${ }^{1,20}$ and poly(ethylene glycol-co-1,4-cyclohexanedimethanol terephthalate) (PETG) ${ }^{18}$, and thermosets (epoxy resins) ${ }^{19}$. These studies revealed that traditional contact techniques based on the use of razor blades introduced damage at the notch root when a natural crack could not be attained. This damage induced an overestimation of fracture toughness values, which increased severely when they were evaluated under elastic-plastic and fully plastic conditions. In addition, the quality of the notches was strongly dependent on the operator's expertise. To evaluate the traditional contact notch-sharpening techniques, an exhaustive analysis of the crack front was performed on every type of polymer previously described. Furthermore, the fracture toughness values of the samples with notches sharpened via contact procedures were compared with those determined from specimens with notches sharpened via a noncontact technique based on femtosecond laser ablation. The femtolaser technique is based on a femtosecond pulsed laser; this created vapor and plasma phases with negligible heat conduction and the absence of a liquid phase. $^{22,23}$ Therefore, this method can remove the material of the notch tip by ablating it with almost no heat dissipation; this prevents melting and the thermal deformations of the surrounding area. Moreover, the femtolaser technique 
produced very sharp cracks, with crack tip radii similar to those achieved via razor blade sharpening. The fracture toughness values determined from the samples with notches sharpened via a femtolaser showed lower values than those obtained from the specimens with notches sharpened via the traditional razor blade technique, when the latter could not generate a natural crack in the polymer. For copolymers, these differences reached values ranging from around $10 \%{ }^{14,16,21}$ when the crack growth initiation parameters were computed under LEFM conditions to 25$75 \%^{14-17}$ and $90 \%{ }^{13,16}$ under elastoplastic fracture mechanics and postyielding fracture mechanics approaches, respectively. For the amorphous polycarbonate, the differences reached about $40 \%$ under LEFM conditions ${ }^{20}$ and up to about $400 \%$ under elastic-plastic situations. ${ }^{17}$ In turn, for the amorphous PETG, the differences ranged between $10-20 \%$ under LEFM application. ${ }^{18}$ The reason for these differences was the presence or absence of damage at the crack front. When contact techniques based on the use of razor blades are used for notch sharpening, the yield stress is locally exceeded; this gives rise to a plastic zone, with the result that the initiation and successive propagation of cracks during the fracture test are through a strain-hardened material with different mechanical properties from those of the virgin material. This contrasts with the lack of any type of damage at the crack front in specimens with notches sharpened via femtolaser. However, the noncontact femtolaser technique has not always provided the lowest fracture toughness values. Salazar et al., ${ }^{19}$ investigating the influence of the notch-sharpening technique on the fracture toughness of an epoxy resin, found that the fracture toughness values of the specimens with notches sharpened via traditional contact techniques such as razor tapping were lower than those obtained from specimens with notches sharpened via a femtolaser. In such a brittle polymer, natural cracks could be attained via traditional contact razor blade techniques such as razor tapping, and the specimens sharpened this way presented crack fronts featuring no damage and the sharpest crack tip radii. Similar conclusions were attained by de Souza et al. ${ }^{11}$ and Agnelli and Horsfall ${ }^{12}$ with brittle PMMA resin.

With this overview, it is clear that there is no a universal notching technique that is valid for every polymer as in the case for metals, and much attention must be paid to the notch-sharpening process to attain reliable fracture toughness values and to prevent overestimations of up to $400 \%$, which could have dramatic consequences on the end-use products of real-life applications. ${ }^{17}$ With this in mind, the key factor for fracture parameter evaluation seems to be the attainment of a natural crack in the specimen and, in cases where this is not possible, the minimization of the damage at the crack front introduced by the notch-sharpening process. In the latter, the operator's skill is crucial when contact notch-sharpening procedures are used. The success rate in notch-sharpening preparation could range from $100 \%$ for an experienced operator to less than $50 \%$ for a novice operator. ${ }^{18}$ With this in mind, two laboratories, one from the Universidad Rey Juan Carlos (URJC) and the other from Centre Català del Plàstic (CCP), collaborated to investigate the degree of reproducibility in the fracture toughness values of styrene-acrylonitrile (SAN) specimens with notches sharpened with different notch-sharpening procedures. In this article, the fracture toughness results are discussed as a function of the crack front features, which resulted from the detailed procedures strictly followed for the application of a specific notch-sharpening technique by the two participating laboratories. To reveal these characteristics, we carried out a deep fractographic study of every single fracture surface and an exhaustive qualitative and quantitative analysis of the crack front of the nontested specimens after sharpening via optical microscopy and scanning electron microscopy (SEM).

\section{EXPERIMENTAL}

Materials

A commercial grade SAN (Kibisan PN-127) was selected for this study. From the pellets, ISO 3167 dumbbellshaped tensile specimens were injection-molded. These were tested in a universal testing machine (SUN2500, Galdabini) equipped with a video extensometer (Mintron OS-65D) at $21 \mathrm{8C}$ and a crosshead rate of $1 \mathrm{~mm} / \mathrm{min}$. Before testing, the tensile specimens were annealed for $24 \mathrm{~h}$ at $110 \mathrm{sC}$ to eliminate the manufacturing orientations. The chosen annealing temperature was slightly higher than the glass-transition temperature of 105 ${ }^{\circ} \mathrm{C}$ and was measured via differential scanning calorimetry through a thermal scan from 30 to $150{ }^{\circ} \mathrm{C}$ at 10 ${ }^{\circ} \mathrm{C} / \mathrm{min}$. Five tensile tests were carried out, and the resulting engineering stress-strain curves revealed typical ductile behavior with a yield stress of $66.8 \pm 1.3 \mathrm{MPa}$, a Young's modulus of $2.99 \pm 0.03 \mathrm{GPa}$, and a Poisson's ratio of $0.38 \pm 0.03$.

Fracture Specimen Preparation and Crack Front Analysis

The CCP laboratory provided prismatic bars with nominal dimensions of $125 \times 12.4 \times 6.2 \mathrm{~mm}^{3}$; these were injection-molded in its facilities. The bars were cut into two pieces to meet the dimensional requirements of the single-edge-notched blend specimens described in ISO13586 ${ }^{2}$ (Figure 1). Both CCP and URJC laboratories machined an initial straight-through slot (prenotch) with a length-to-width ratio of 0.45 ; this terminated in a V-notch with a root radius of $0.25 \pm 0.05 \mathrm{~mm}$ and a notch angle of $45 \pm 1^{\circ}$. The sharp crack was introduced by contact methods such as razor tapping, razor sliding, and razor broaching and the femtolaser noncontact procedure. The following notch-sharpening procedures were used.

Tapping. The specimens were sharpened by tapping with a new razor blade placed in the prenotch with the aim of generating a natural crack. In brittle polymer specimens, a natural crack can be generated by this process, but some skill is required to prevent too long of crack or local damage. ${ }^{1-4,7}$ This notch-sharpening procedure was performed by both laboratories, CCP and URJC.

Sliding. This technique consisted of the sliding of a fresh, new steel razor blade across the root of the 
prenotch. ${ }^{2,5,7,8}$ Apart from sliding, some pressing was necessary to achieve the notch-sharpening length. This sharpening technique was only used by CCP.

Broaching. Notch sharpening via broaching was done with a sharp tool that was repeatedly drawn across the machined prenotch; this extended the notch by a small increment on each pass until the notch extension criterion was fulfilled. This notch-sharpening technique was similar to that used by CEAST notching machines for Izod and Charpy impact testing notching. Although the CCP laboratory used a CEAST notching machine with the head modified to accept a Stanley heavy-duty utility blade, the URJC laboratory used a homemade machine with a triangular industrial blade that was $0.2 \mathrm{~mm}$ thick. Both laboratories replaced the blades very frequently.

For the contact notch-sharpening techniques, instructions were written in the form of detailed steps that were strictly followed by both laboratories; this was done with the aim of minimizing the damage at the crack front and the dependence upon the operator's skill. On the other hand, the following femtolaser sharpening procedure was a noncontact, automated technique where the operator only played a small role.

Femtolaser. The prenotch sharpening was carried out with a femtosecond pulsed laser ${ }^{22,23}$ with a commercial Ti/sapphire oscillator (Tsunami, Spectra Physics) plus a regenerative amplifier system (Spitfire, Spectra Physics) on the basis of the chirped pulse amplification (CPA) technique. Linearly polarized 120-fs pulses at $395 \mathrm{~nm}$ with a repetition rate of $1 \mathrm{kHz}$ were produced.

The scanning speed was $130 \mu \mathrm{m} / \mathrm{s}$. Three passes were carried out with a pulse energy of $0.004 \mathrm{~mJ}$. The sharpening length inserted by the femtolaser was around $500 \mu \mathrm{m}$. This noncontact sharpening procedure was repeatable and practically independent of the operator. The specimens were sharpened at the Servicio Laser of the Salamanca University.

Independently of the sharpening procedure, the ratio $a_{0} / W$ was within $0.45-0.55$, where $a_{0}$ is to the total initial crack length after sharpening and $W$ is the width of the prismatic specimen (Figure 1 ).

The morphology and dimensions of the crack tip radius after sharpening and the area behind it, that is, the crack front, were analyzed via SEM with JEOL JSM-5610 and Hitachi S-3400 N equipment. Some extra specimens were sharpened for each type of sharpening method that could not be tested because they were partially destroyed in the preparation process for SEM analysis. Before examination, preparation was needed and consisted of the sectioning of the bulk SAN into films with thicknesses in the range between 15 and 20 $\mu \mathrm{m}$ with a microtome (Leica RM2255 rotary microtome). Both the resulting sections and the polished bulk surface left behind were analyzed. Specifically, the thin films were picked up and mounted on microscope slides to be inspected via transmitted light microscopy or were platinum sputter-coated for SEM. Quantitative measurements related to the crack front features of a specific notch-sharpening technique were obtained from the inspection of at least three different samples.

In addition, the fracture surfaces of the tested specimens were observed through optical microscopy and SEM to measure the sharpening length, to analyze the quality of the notch, and to determine the micromechanisms of failure.

Fracture Tests

Fracture tests were performed on a three-point bending configuration with a loading-span (S)-to-specimenwidth ratio of 4 (Figure 1 ) at a crosshead speed of $1 \mathrm{~mm} / \mathrm{min}$. The CCP laboratory used an electromechanical universal testing machine (Galdabini Sun2500) with a load cell of $\pm 1 \mathrm{kN}$, whereas the URJC laboratory used an MTS Alliance RF/100 electromechanical universal testing machine equipped with a load cell of $\pm 5 \mathrm{kN}$.

Under these experimental conditions, the mechanical response of SAN fulfilled the LEFM requirements, and the guidelines of ISO $13586: 2000^{2}$ were followed to determine the fracture toughness and the critical energy release rate.

RESULTS

Fracture Parameters with Tapping as the Notch-Sharpening Procedure

CCP Results. The CCP laboratory tested 27 samples with notches sharpened via tapping with a razor blade at $23^{\circ} \mathrm{C}$; this resulted in two different load-displacement curves (Figure 2). A total of 18 out of 27 specimens presented curves with the presence of either a prepeak force followed by a drop in force, termed as pop-in, or with a shoulder in the curve followed by stiffness reduction [Figure 2(a)]. When pop-in occurred, the crack was initiated, and its coordinates were used to define crack initiation. ${ }^{2}$ Interestingly, pop-in occurred at the same force level for all of the specimens showing this mechanical response. In contrast, the remaining specimens presented a linear elastic response until rupture or a semibrittle behavior [Figure 2(b)], and the peak force or the $5 \%$ offset coordinates were used for crack initiation. ${ }^{2}$ Tables I and II show the fracture toughness and critical energy release rate together with their corresponding standard deviations of the SAN specimens with notches sharpened via razor tapping. As shown, the fracture parameters evaluated from the specimens with no pop-in in the load-displacement records were two and five times bigger than those obtained from specimens with pop-in, respectively, when computed in terms of the stress intensity factor and the energy 
release rate.

The fracture surfaces of the specimens with and without pop-in are illustrated in Figure 3(a,b), respectively. In the specimens with pop-in in the load-displacement curves, the fracture surface displayed mirror, mist, and hackle morphologies; this is typical of amorphous brittle materials. ${ }^{24-26}$ These three patterns were related to the mechanical response. The initial crack growth produced the smooth mirror region, which was connected with the prepeak force of the load-displacement curves [Figure 2(a)]. Immediately after, some crack arrest occurred; this marked the boundary between the mirror and mist zones. Upon loading, the

crack progress accelerated; this created a dimpled surface known as mist. Finally, instability occurred, and this caused the crack to branch out and produce the rough hackle region, characterized by elongated markings that proceed in the direction of crack propagation. This morphology contrasted with that shown by the specimens with no pop-in in the load-displacement curves [Figure 2(b)], where only one single rough area, similar to the hackle region of Figure 3(a), was observed.

URJC Results. Figure 4 shows the load-displacement records derived from the batch of samples with notches sharpened via razor tapping in the URJC laboratory. First, none of the load- displacement curves displayed pop-in, and the fracture parameters were calculated by either the peak force or the $5 \%$ offset force and are collected in Tables I and II. As expected, the fracture toughness and the critical energy release rate values were similar to those obtained by CCP in which no pop-in was seen. Second, only 6 out of 22 tests fulfilled all the ISO13586 requirements. This poor success rate of only 30\% and the absence of pop-in in the load-displacement diagrams are noteworthy as the notch-sharpening technique via tapping carried out in the URJC laboratory was performed with the same guidelines as used in the CCP laboratory. Once more, the skill and training of the operator played a decisive role in the notch-sharpening quality.

The fractographic analysis performed on every single tested specimen showed the same morphology exhibited by the samples tested at CCP with no pop-in in the load-displacement records [Figure 3(b)], that is, a rough region with relatively large irregularly oriented facets, usually separated by large steps aligned parallel to the main direction of crack propagation.

Fracture Parameters with Sliding as the Notch-Sharpening Procedure

CCP Results. Figure 5 illustrates the load-displacement diagrams obtained from the batch of specimens with notches sharpened via razor sliding in the CCP laboratory. A total of 15 samples were tested, from which 11 presented pop-in in the load-displacement records [Figure 5(a)], and the rest displayed a semibrittle response [Figure 5(b)]. The fracture toughness and the energy release rate of the samples that showed no pop-in in the load-displacement curves were two and four times bigger than those determined from the specimens in which pop-in occurred in the load-displacement records, respectively. Moreover, the fracture parameters of the specimens with notches sharpened via sliding were identical to those obtained in samples with notches sharpened via tapping (Tables I and II).

The fracture surfaces of the specimens with notches sharpened via razor sliding, with and without pop-in, are illustrated in Figure 6(a,b), respectively. As in the samples with notches sharpened via razor tapping, the specimens with pop-in in the load-displacement curves exhibited the mirror, mist, and hackle patterns [Figure 6(a)], but the samples that showed no pop-in in the load-displacement records displayed only one single rough zone [Figure 6(b)].

Fracture Parameters with Broaching as the Notch-Sharpening Procedure

Fifteen and seven samples with notches sharpened via razor broaching were tested in the CCP and URJC laboratories, respectively. The load-displacement records obtained in both laboratories were very similar (Figure 7), with a linear and elastic response until rupture. Consequently, the fracture parameters were calculated from the peak force. No differences were observed in the fracture toughness (Table I) or the critical energy release rate (Table II) values determined in both laboratories. Furthermore, the fracture parameters were identical to those obtained in samples with notches sharpened via either razor tapping or razor sliding where no pop-in occurred in the load-displacement records.

The fracture surfaces of the specimens with notches sharpened via broaching in both laboratories were similar (Figure 8) and, accordingly, were identical to the morphology of the specimens with notches sharpened via razor tapping [Figure 3(b)] and razor sliding [Figure 6(b)] with no pop-in in the load-displacement diagrams.

Fracture Parameters with a Femtolaser as the Notch-sharpening Procedure

The batches of samples with notches sharpened via a femtolaser were prepared by Servicio Laser of the Salamanca University for both the CCP and URJC laboratories, so there was no influence of the operator in this noncontact sharpening procedure. Five and three specimens were tested in the CCP and URJC laboratories, respectively. As expected, the mechanical response obtained in both laboratories was exactly the same. The load-displacement curves displayed a semibrittle behavior; they became unstable just after they reached maximum load (Figure 9). The fracture toughness and energy release rate were calculated from the peak force because it preceded the 5\% 
offset coordinates in every single test. ${ }^{2}$ The values determined in both laboratories presented minimal differences (Tables I and II). The fracture toughness and energy release rate of the specimens with notches sharpened by the femtolaser were $20 \%$ lower than those obtained from the specimens with notches sharpened via razor broaching or razor tapping with no pop-in in the load-displacement records but were two and four times bigger than the fracture toughness of the specimens with notches sharpened via razor tapping with pop-in in the loaddisplacement diagrams, respectively. The fracture surfaces were completely smooth and plain with no characteristic features close to the notch (Figure 10).

\section{DISCUSSION}

Analysis of the fracture parameters on the samples with notches sharpened via contact techniques revealed that the results could be divided into two groups: those obtained from specimens where no pop-in occurred in the load-displacement records and those determined from samples where pop-in occurred. The first group was formed from specimens with notches sharpened via the three types of contact procedures, that is, razor tapping, razor sliding, and razor broaching; the second group was only formed from specimens prepared with methods performed by an operator, that is, razor tapping and sliding. The fracture parameters accomplished in the specimens of the first group were noticeably higher, two and five times bigger than those of the samples of the second group, when computed in terms of the fracture toughness and critical energy release rate, respectively (Tables I and II). Specifically, the fracture toughness and the energy release rate of the specimens that showed pop-in the load-displacement records were $1.3 \pm 0.2 \mathrm{MPa} \mathrm{m}^{1 / 2}$ and $500 \pm 100 \mathrm{~J} / \mathrm{m}^{2}$, respectively; that is, they were $20 \%$ higher than the reported values for pure polystyrene (PS; fracture toughness $=1.05 \mathrm{MPa} \mathrm{m}{ }^{1 / 2}$, which corresponded to a fracture energy of $\left.340 \mathrm{~J} / \mathrm{m}^{2}\right) \cdot{ }^{27-30}$ Evidently, the SAN fracture parameters must have been larger than those of the pure PS as the former was a copolymer consisting of styrene and acrylonitrile with a relative composition of 70-80 wt \% styrene and 20-30 wt \% acrylonitrile. ${ }^{31}$ Thus, for an acrylonitrile content as high as $30 \mathrm{wt} \%$, an increase in the fracture toughness of $20 \%$ compared with the pure PS, as obtained in SAN specimens with notches sharpened via razor tapping and sliding with pop-in in the loaddisplacement records, was more reasonable than values five times larger, as in the case of the SAN samples with notches sharpened via razor tapping, sliding, or broaching with no pop-in in the fracture curves.

To shed more light on the cause of such large fracture values in the specimens with notches sharpened via razor sliding, razor tapping, and broaching with no pop-in in the load-displacement curves, the crack front of the nontested samples after notch sharpening was evaluated. Figures 11 and 12 show the crack front of the specimens with notches sharpened via razor tapping and razor broaching, respectively. The crack front of the specimens with notches sharpened via razor sliding was analogous to that of the samples with notches sharpened via razor tapping. First, there was an area ahead of the crack tip with a different morphology. A higher magnification analysis evidenced the presence of several crazes (Figure 13). The presence of crazes indicated that during the application of the contact notch-sharpening procedures, the craze initiation stress was locally exceeded. Crazing is a form of localized plastic deformation in glassy polymers and is often mistaken for cracks, but there are major differences between them: the craze face is covered by a web of microfibrils that bridge the craze surfaces and enable the craze to support relatively high stresses. ${ }^{32-34}$ The separation between microfibrils is roughly $50 \mathrm{~nm}$, and the distance between the craze surfaces is $300 \mathrm{~nm}$. When cracks develop, they invariably originate by the breakdown of the craze fibril structure to form large voids; this leaves behind on the fracture surface a patch or mackerel pattern. ${ }^{34}$ This pattern was observed in the analysis via SEM (Figure 14) and light microscopy [Figures 3(b), 6(b), and 8] of the fracture surfaces of the specimens with notches sharpened via razor sliding, tapping, or broaching that presented no pop-in in the load-displacement records. Once the crack propagates beyond the original boundaries of the craze, a new craze is generated at its tip. The craze is a plastic zone at the crack tip and is considered an important source of both fracture energy and fracture toughness. ${ }^{32-34}$ Therefore, the presence of bundles of crazes, whose extensions ahead of the crack tip were $300 \pm 100$ and $80 \pm 10 \mu \mathrm{m}$ for the specimens with notches sharpened via razor tapping and razor sliding, respectively (Table III), was the reason for the large fracture parameters in the specimens with notches sharpened via contact procedures with no pop-in in the load-displacement records. Because of the size of the multiple crazing area, the fracture parameters of the samples with notches sharpened via razor broaching should have been lower than those of the specimens sharpened via razor tapping or sliding, but this was not the case; only a small difference was seen. This fact showed that the crack tip radius also played a crucial role in the fracture toughness. The crack tip radii of the specimens with notches sharpened via broaching were eight times bigger than those of the specimens with notches sharpened via tapping or sliding (Table III). This seemed to indicate that the combination of small multiple crazing zones and large crack tip radii could be equivalent to the combination of large multiple crazing zones and very sharp crack tip radii. This same trend was also observed by researchers in the analysis of the effect of the notch-sharpening technique on poly(ethylene terephthalate) with cyclohexanedimethanol (PETG). ${ }^{18}$ In that study, the specimens with the smallest crack tip radii did not always provide the lowest fracture toughness values. The size of the 
damage zone played an important role, and the same occurred in the evaluation of the fracture parameters as a function of the size of the damage area. The conclusions drawn from that work were that the dimensions of both the crack tip radius and the damage area ahead of the crack tip both governed the fracture behavior. Indeed, more work concerning this issue is needed.

From this point, we elucidated why the fracture toughness values of the specimens with notches sharpened via razor tapping and sliding where pop-in occurred in the load-displacement records were so small. This was done through analysis via SEM (Figure 15) of the mirror area observed in the fracture surfaces analyzed via light microscopy [Figures 3(a) and 6(a)]. The morphology was quite different than that observed in Figure 14. However, a patch pattern was still observed, although it was much finer; this indicated that crazes were also present. Indeed, the presence of three zones and, specifically, the development of the mirror area, evidenced that the crack initiation occurred in one single craze in the specimens where pop-in took place over the crack initiation through the bundle of crazes, as in the samples where no pop-in happened. This behavior was also described by Martínez and Maspoch ${ }^{34}$ in the fracture behavior of PS with different lubricant contents.

With respect to the technical details of the contact notching procedure for attaining crack initiation through one single craze or a bundle of crazes, when notch sharpening was performed in an automated manner, that is, via broaching, only bundles of crazes were formed at the crack front. The attainment of one single craze at the crack front was only accomplished with the notch-sharpening techniques such as razor tapping and sliding and was strongly dependent on the operator's skill. Fracture initiation through one single craze was obtained only in the specimens with notches sharpened in the CCP laboratory.

Finally, the fracture parameters of the specimens with notches sharpened via a noncontact procedure such as the femtolaser presented larger values than those achieved from the samples in which the crack initiation took place through one single craze; this led to the appearance of pop-in in the load-displacement records. However, the values were lower than those determined from specimens in which the crack initiation occurred through a bundle of crazes where no pop-in was present in the load-displacement diagrams (Tables I and II). Analysis of the crack front revealed a small area of damage ahead of the crack tip [Figure 16(a)] that was $20 \mu \mathrm{m}$ in size (Table III) and was related to partially melted material [Figure 16(b)]. This tiny damaged zone, together with a crack tip radii twice as large as those of the specimens sharpened via razor sliding and pressing, accounted for the ranking of the results.

\section{CONCLUSIONS}

The CCP and URJC laboratories collaborated to investigate the influence of the notch-sharpening technique on the fracture parameters of SAN. Three contact notch-sharpening techniques, razor tapping, razor sliding, and razor broaching, and a noncontact procedure, a femtolaser, were investigated. The fracture parameters determined from the samples with notches sharpened via the contact techniques showed two behaviors. In one case, the loaddisplacement records presented pop-in, which resulted in the lowest fracture toughness and fracture energy values, and in the other, no pop-in appeared in the load-displacement curves; this led leading to the highest fracture toughness and fracture energy values. Crack front analysis revealed that the crack front of all of the nontested specimens with notches sharpened via the three types of contact notch-sharpening techniques presented bundles of crazes. Low fracture toughness values were attained because the crack initiation occurred in one single craze; this led to fracture surfaces with mirror, mist, and hackle patterns. On the other hand, large fracture parameters were achieved when the crack initiation took place through a bundle of crazes; this produced a fracture surface formed by one single rough surface identified by a patch or mackerel pattern. The specimens with the lowest fracture toughness values were notch sharpened via contact techniques performed by an operator, that is, razor tapping and razor sliding. Moreover, a clear influence of the operator's expertise was evidenced, as this behavior was not reproduced in one of the laboratories. Fracture parameters were not only controlled by the existence and extent of damage but also by the crack tip radius. The results show that in terms of the fracture toughness values, the combination of a large damaged area with a very sharp crack was equivalent to a small damaged area with a large crack tip radius.

Finally, the fracture values of the specimens with notches sharpened via the noncontact technique of the femtolaser were found to be between those obtained in the specimens with notches sharpened via the contact techniques with and without pop-in in the load-displacement curves. In this case, a very small damaged area was found to be present at the crack front that consisted of partially melted material. Furthermore, the crack tip radii were two times bigger than those of the sharp cracks attained via razor tapping and sliding.

\section{ACKNOWLEDGMENTS}

The authors are indebted to the Ministerio de Economia y Competitividad of Spain for its financial support through project MAT2012-37762. 


\section{REFERENCES}

1. Williams, J. G. In Fracture Mechanics Testing Methods for Polymers, Adhesives and Composites; Moore, D.

R., Pavan,

A., Williams, J. G., Eds.; Elsevier Science and European Structural Integrity Society: Amsterdam, 2001; p 11.

2. International Standards Organization. Plastics- Determination of Fracture Toughness (GIC and KIC) - Linear Elastic Fracture Mechanics (LEFM) Approach; ISO 13586 2000; International Standards Organization: Geneva, Switzerland, 2000.

3. International Standards Organization. Plastics - Determination of Fracture Toughness (GIC and KIC) at Moderately High Loading Rates (1 m/s); ISO 17281 2002; International Standards Organization: Geneva, Switzerland, 2002.

4. Pavan, A. In Fracture Mechanics Testing Methods for Polymers, Adhesives and Composites; Moore, D. R., Pavan, A., Williams, J. G., Eds.; Elsevier Science and European Structural Integrity Society: Amsterdam, 2001; p 27.

5. Hale, G. E.; Ramsteiner, F. In Fracture Mechanics Testing Methods for Polymers, Adhesives and Composites; Moore, D. R., Pavan, A., Williams, J. G., Eds.; Elsevier Science and European Structural Integrity Society: Amsterdam, 2001; p 123.

6. Clutton, E. In Fracture Mechanics Testing Methods for Polymers, Adhesives and Composites; Moore, D. R., Pavan, A., Williams, J. G., Eds.; Elsevier Science and European Structural Integrity Society: Amsterdam, 2001; p 177.

7. ASTM D 5045-99. Standard Test Methods for Plane-Strain Fracture Toughness and Strain Energy Release Rate of Plastic Materials; ASTM International: West Conshohocken, PA, 1999.

8. ASTM D6068-96(2002) e1. Standard Test Method for Determining J-R Curves of Plastic Materials; ASTM International: West Conshohocken, PA, 2002.

9. ASTM E 1820-06: Standard test method for measurement of fracture toughness. ASTM International: West Conshohocken, PA, 2007

10. Peres, F. M.; Schön, C. G.; Tarpani, J. R. Polym. Test. 2010, 29, 667.

11. de Souza, J. M.; Yoshimura, H. N.; Peres, F. M.; Schön, C. G. Polym. Test. 2012, 31, 834.

12. Agnelli, S.; Horsfall, I. Eng. Fract. Mech. 2013, 101, 59.

13. Martínez, A. B.; Segovia, A.; Gámez-Pérez, J.; Maspoch, M. L. Eng. Fract. Mech. 2009, 76, 1247.

14. Salazar, A.; Rodríguez, J.; Segovia, A.; Martínez, A. B. Polym. Test. 2010, 29, 49.

15. Salazar, A.; Segovia, A.; Martínez, A. B.; Rodríguez, J. Polym. Test. 2010, $29,824$.

16. Salazar, A.; Rodríguez, J.; Segovia, A.; Martínez, A. B. Eur. Polym. J. 2010, 46, 1896.

17. Salazar, A.; Rodríguez, J.; Martínez, A. B. Eng. Fract. Mech. 2013, 101, 10.

18. Martínez, A. B.; León, N.; Arencón, D.; Rodríguez, J.; Salazar, A. Polym. Test. 2013, 32, 1244.

19. Rodríguez, J.; Salazar, A.; Gomez, F. J.; William, J. G.; Patel, Y. Eng. Fract. Mech. 2015, 149, 402.

20. Salazar, A.; Rodríguez, J.; Martínez, A. B. Indian J. Mater. Sci. 2013, 2013, 1.

21. Martínez, A. B.; Arencón, D.; Rodríguez, J.; Salazar, A. Polym. Test. 2014, 36, 75.

22. Chichkov, B. N.; Momma, C.; Nolte, S.; von Alvensleben, F.; Tünnermann, A. Appl. Phys. A 1996, 63, 109.

23. Moreno, P.; Méndez, C.; García, A.; Arias, I.; Roso, L. Appl. Surf. Sci. 2006, 252, 4110.

24. Hulk, D. Fractography: Observing, Measuring and Interpreting Fracture Surface Topography; Cambridge University Press: Cambridge, United Kingdom, 1999.

25. Sahimi, M. In Heterogeneous Materials II: Nonlinear and Breakdown Properties and Atomistic Modeling; Antman, S. S., Marsden, J. E., Sirovich, L., Wiggins, S., Eds.; SpringerVerlag: Berlin, 2003.

26. Hertzberg, R. W.; Vinci, R. P.; Hertzberg, J. L. Deformation and Fracture Mechanics of Engineering Materials, 5th ed.; Wiley: Hoboken, NJ, 2012.

27. Parvin, M.; Williams, J. G. J. Mater. Sci. 1976, 11, 2045.

28. Serrano, A. M.; Welsch, G. E.; Gibala, R. Polym. Eng. Sci. 1982, 22, 946.

29. Williams, J. G. Fracture Mechanics of Polymers; Ellis Horwood: Chichester, United Kingdom, 1984.

30. Cotterell, B. Fracture and Life; Imperial College Press: London, United Kingdom, 2010.

31. Maul, J.; Frushour, B. G.; Kontoff, J. R.; Eichenauer, H.; Ott, K. H. In Ullmann's Encyclopedia of Industrial Chemistry; Wiley-VCH: Weinheim, 2000.

32. Kambour, R. P. J. Polym. Sci. Part A-2: Polym. Phys. 1996, 4, 17. 
33. Kambour, R. P. J. Polym. Sci. Macromol. Rev. 1973, 7, 1.

34. Martínez, A. B.; Maspoch, M. Ll. Anal. Mec. Fract. 1990, 7, 156. 

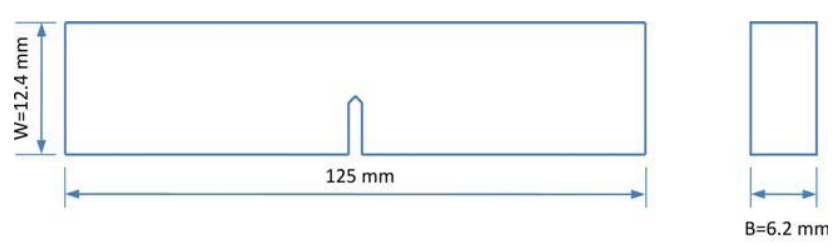

$\Theta=45^{\circ}$
Radio máx $=0.25 \mathrm{~mm}$$\underset{\mathrm{a}_{0}=0.45 \mathrm{~W}}{\hookrightarrow}$

$\mathrm{N}<\mathrm{W} / 10, \mathrm{~N}=1.6 \mathrm{~mm}$

$\mathrm{N}<\mathrm{W} / 10, \mathrm{~N}=1.6 \mathrm{~mm}$
Figure 1. Schematic drawing of the single-edge-notched bend specimen. B thickness, $\mathrm{W}$ width, $\mathrm{N}$ separation between the lateral surfaces of the notch, and $\mathrm{u}$ is the angle of the V-notch 

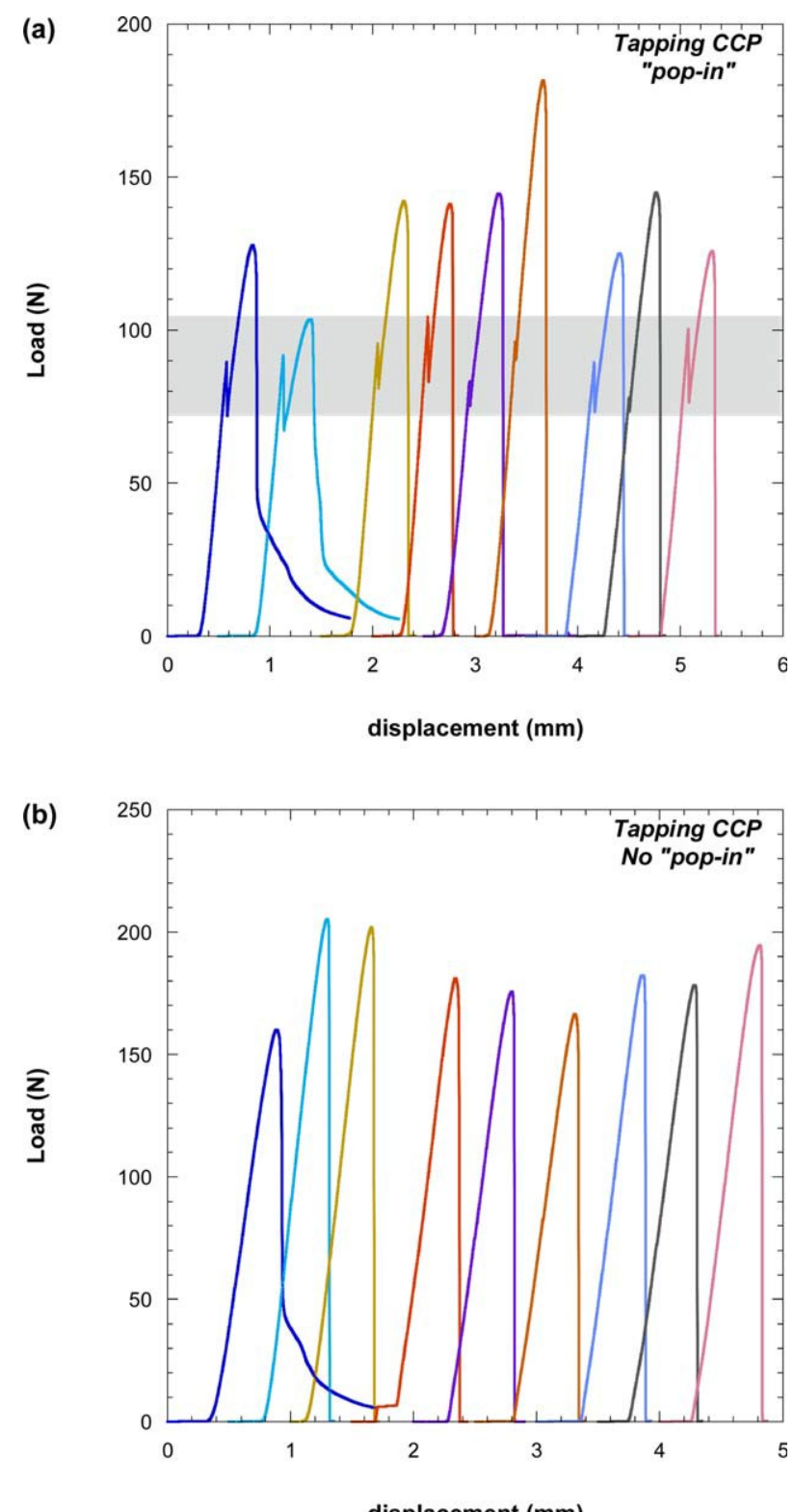

Figure 2. Two types of representative load-displacement curves obtained from the batch of specimens with notches sharpened via razor tapping in the CCP laboratory. (a) Pop-in occurred, and its coordinates were used to define crack initiation. (b) No pop-in occurred, and the peak force or $5 \%$ offset coordinates were used for crack initiation definition. The shaded area in panel a indicates the load range within which pop-in occurred. 


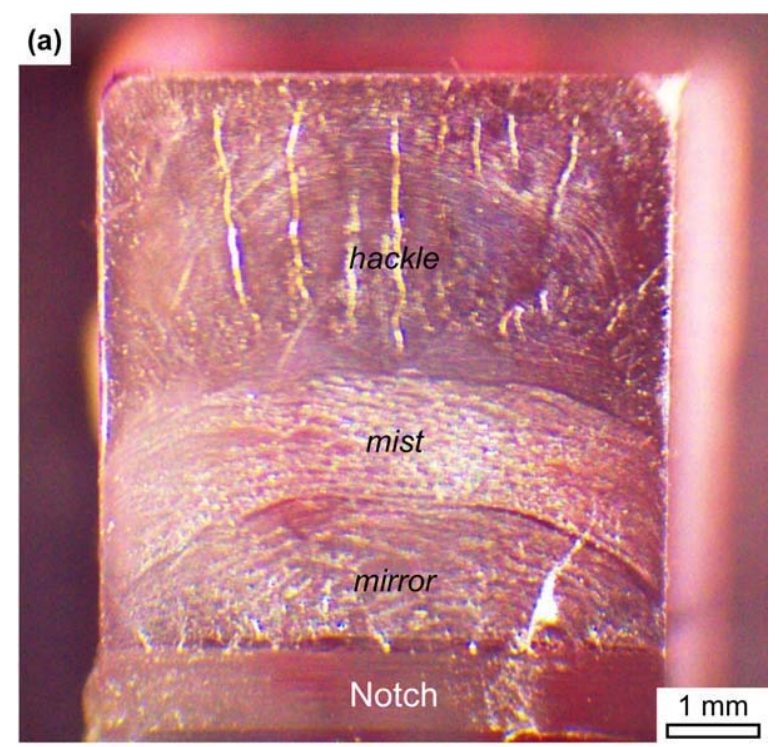

(b)

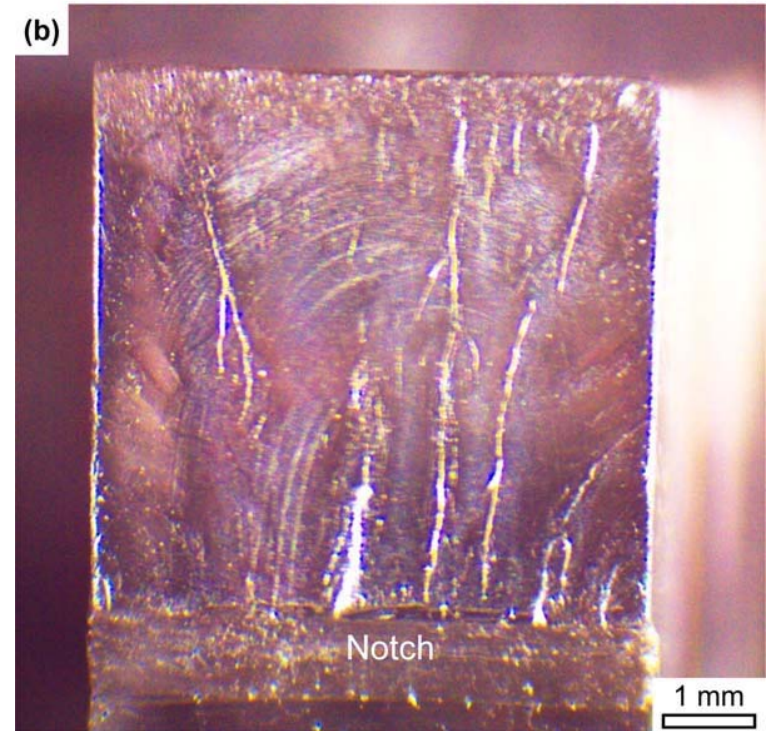

Figure 3. Fractographic analysis via light microscopy of the specimens with notches sharpened via razor tapping in the CCP laboratory. (a) Specimens with pop-in in the load-displacement curves exhibited mirror, mist, and hackle patterns. (b) Specimens with no pop-in in the load- displacement curves presented only a rough surface. 


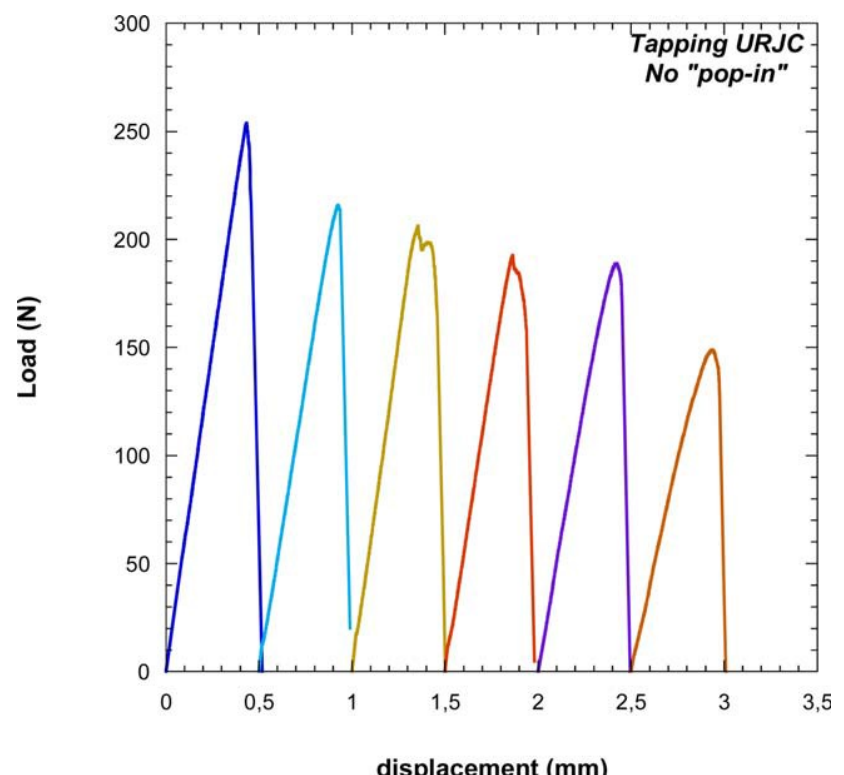

Figure 4. Representative load-displacement curves obtained from the batch of specimens with notches sharpened via razor tapping in the URJC laboratory 
(a)

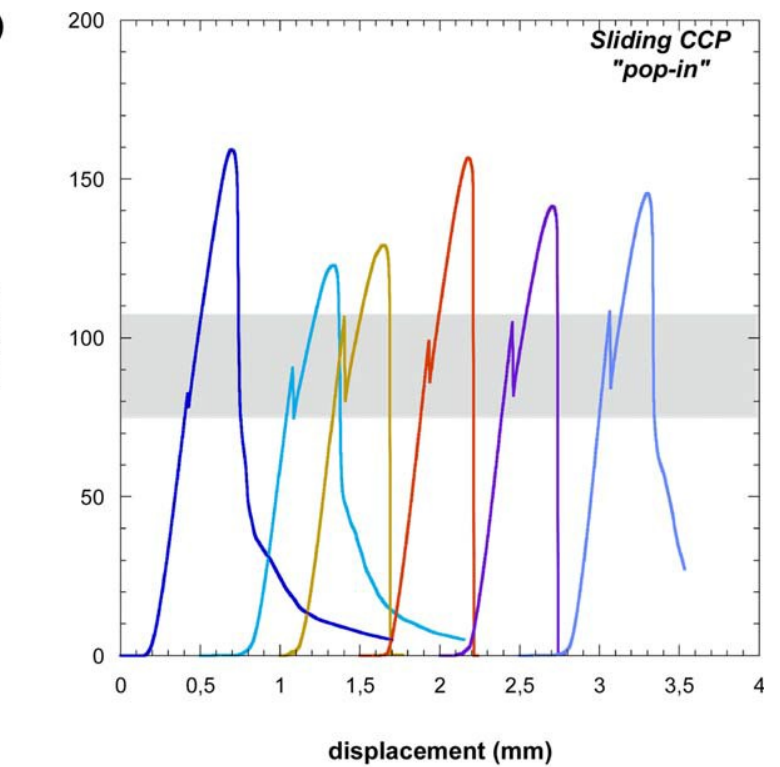

(b)

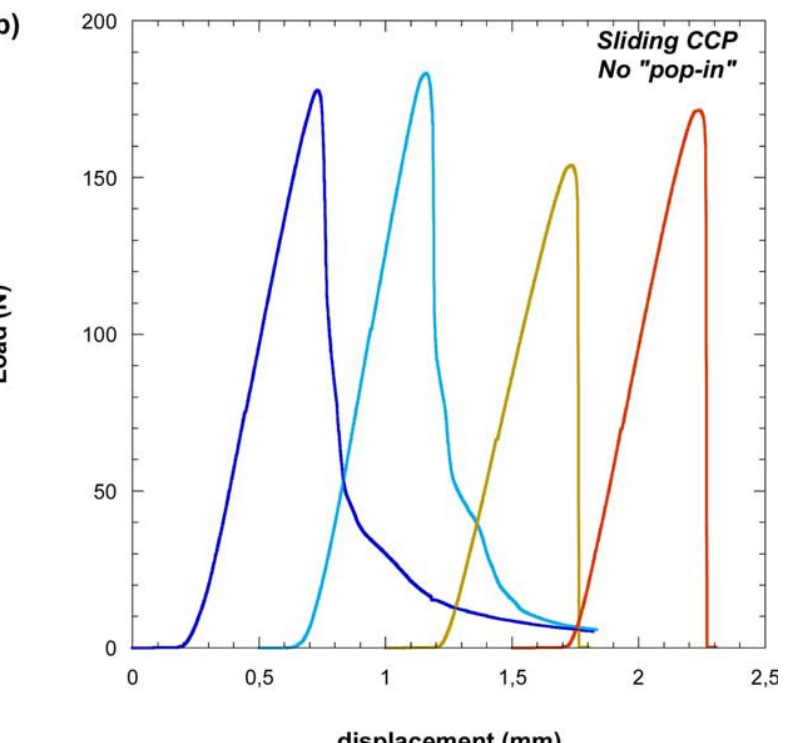

Figure 5. Two types of characteristic load-displacement curves obtained from the batch of specimens with notches sharpened via razor sliding in the CCP laboratory. (a) Pop-in occurs. (b) No pop-in occurs. The shaded area in panel a indicates the load range within which pop-in occurs. 

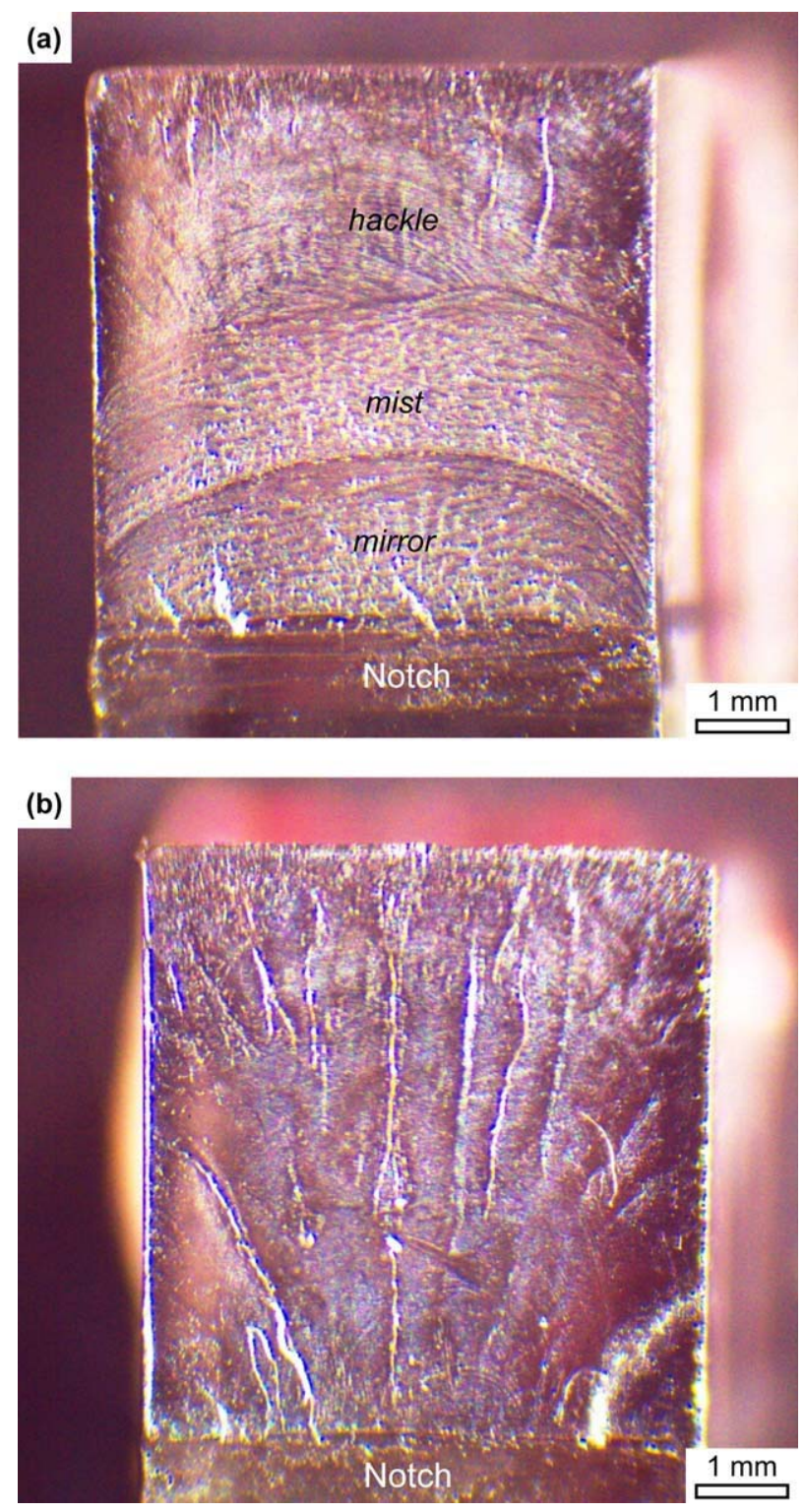

Figure 6. Fractographic analysis via light microscopy of the specimens with notches sharpened via razor sliding in the CCP laboratory (a) Specimens with pop-in in the load-displacement curves exhibited mirror, mist, and hackle patterns. (b) Specimens with no popin in the load-displacement curves showed only a rough surface. 
(a)

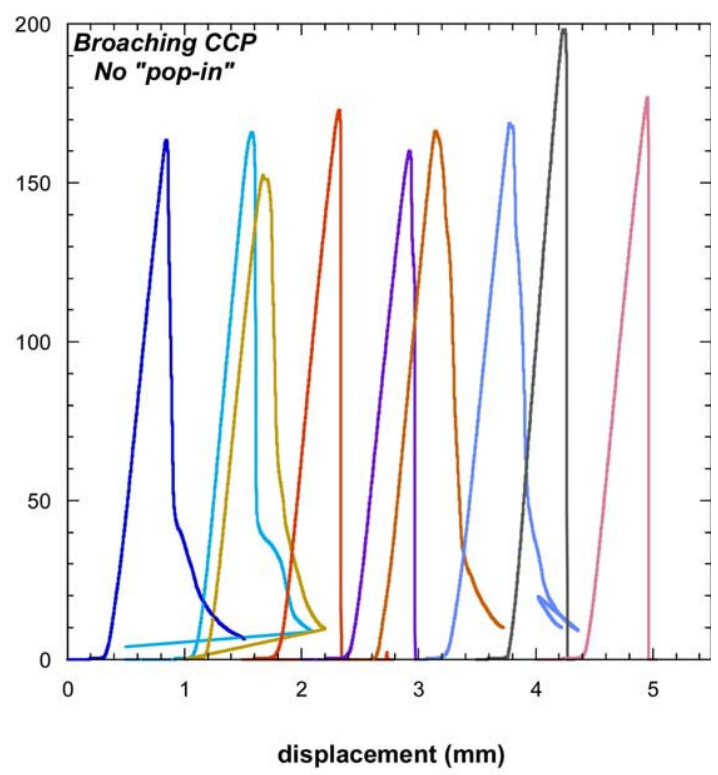

(b)

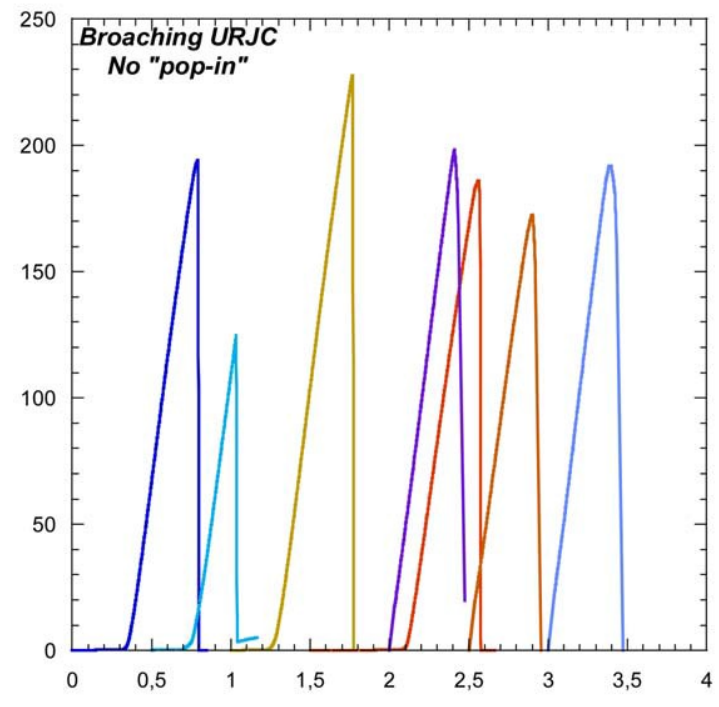

displacement (mm)

Figure 7. Characteristic load-displacement curves determined from the batch of specimens with notches sharpened via razor broaching in the (a) CCP and (b) URJC laboratories. 


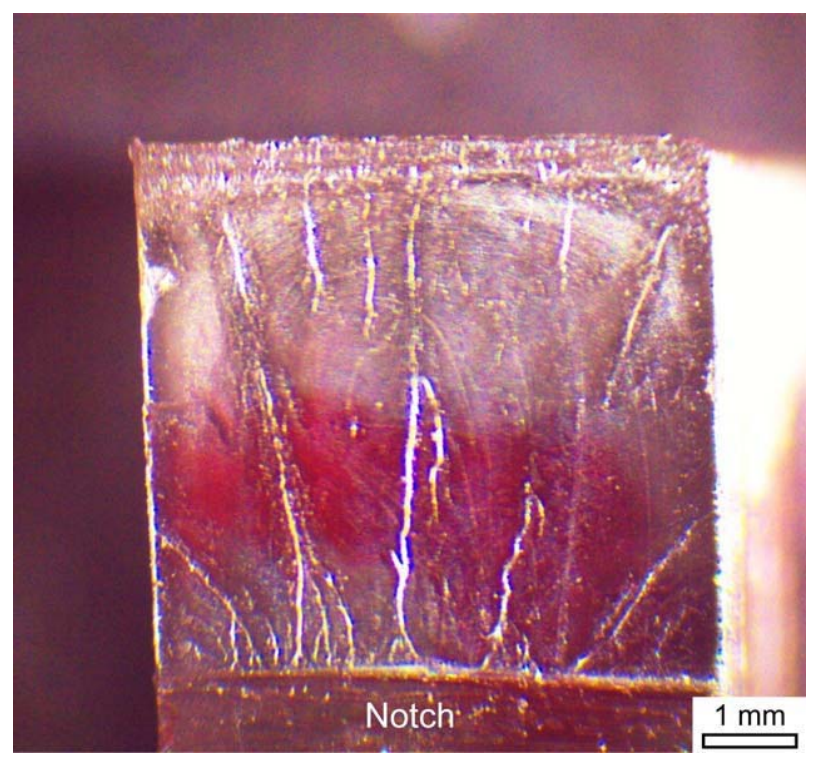

Figure 8. Fracture surface obtained from the specimens with notches sharpened via razor broaching 

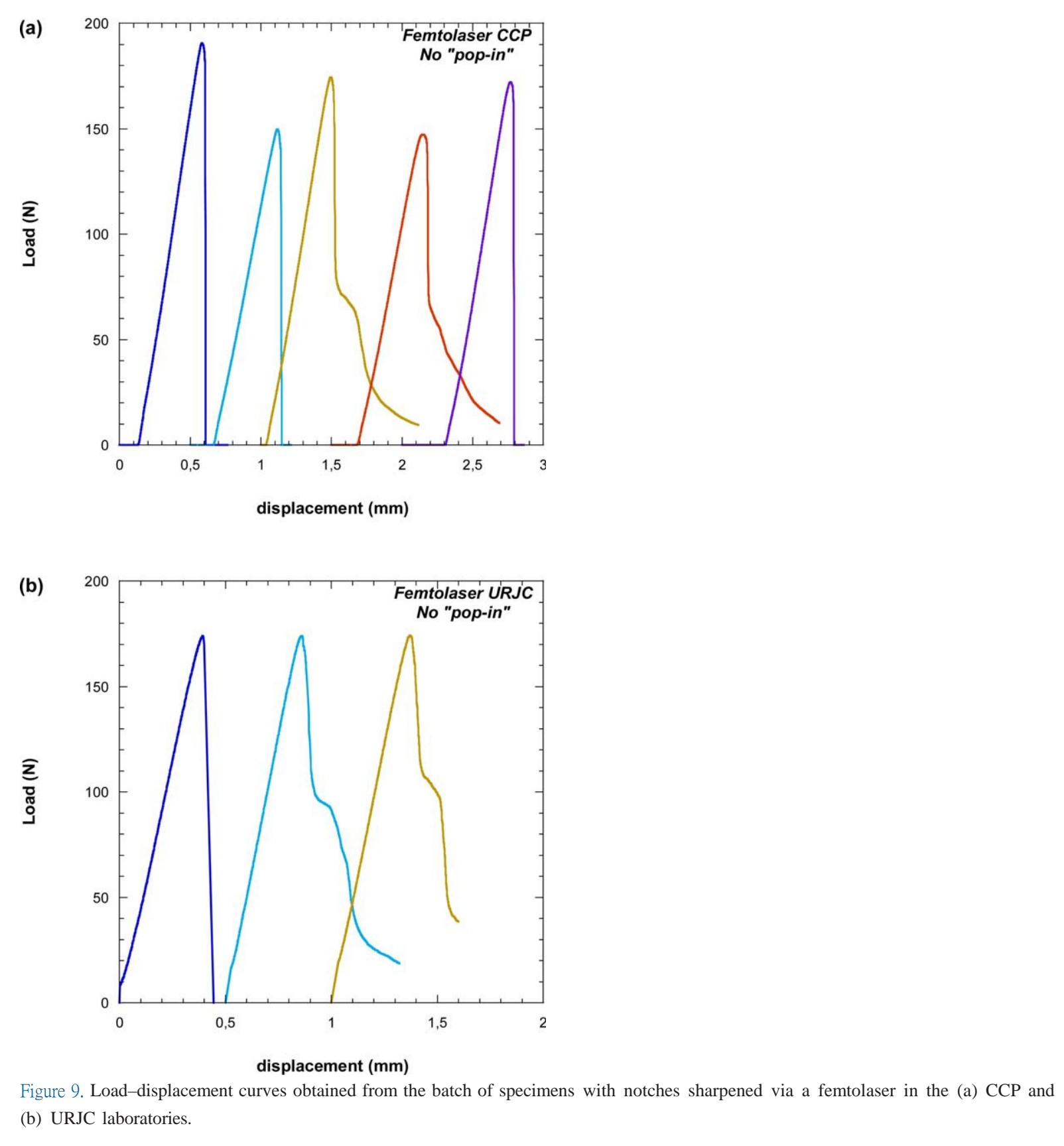


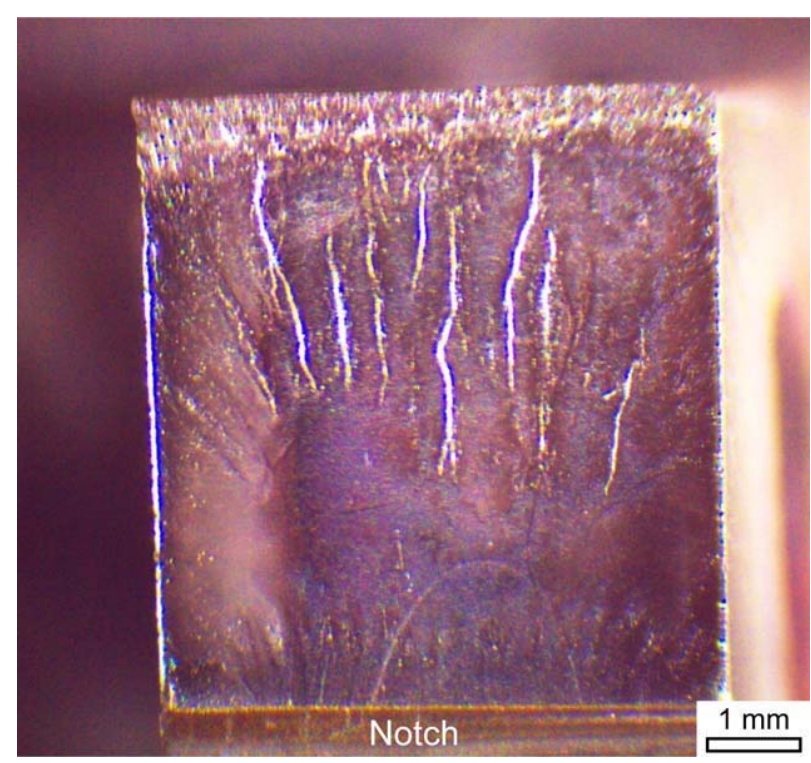

Figure 10. Fracture surface obtained from the specimens with notches sharpened via a femtolaser. 
(a)

$10 \mu \mathrm{m}$

(b)

$1 \mu \mathrm{m}$

Figure 11. SEM micrographs of the crack front of nontested specimens with notches sharpened via razor tapping: (a) panoramic view and (b) detail of the damage ahead of the crack tip. The arrow points out the crack tip in panel a. 
(a)

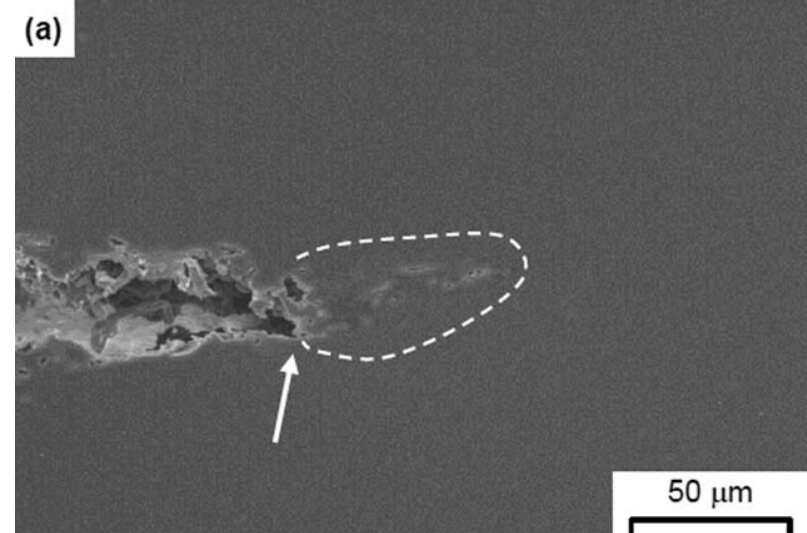

(b)

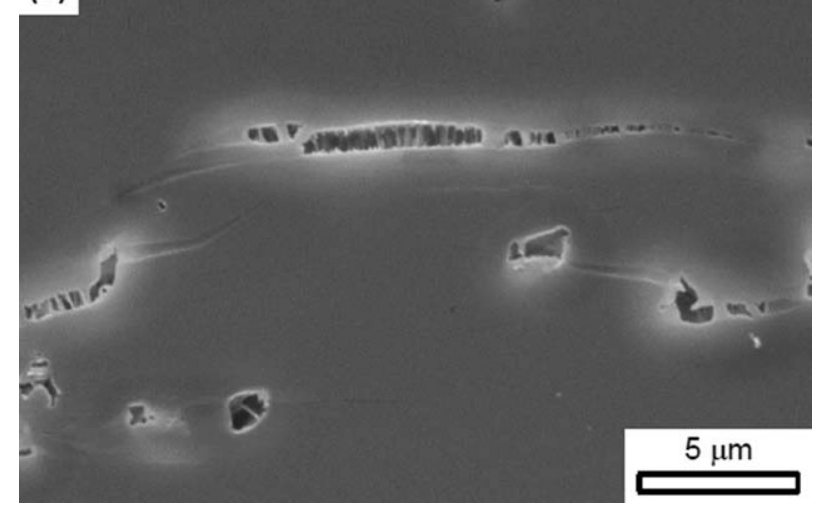

Figure 12. Crack front of nontested specimens with notches sharpened via razor broaching: (a) panoramic view and (b) detail of the damage ahead of the crack tip. The arrow points out the crack tip, and the damaged area beneath the crack tip is outlined by white dotted lines in panel a. 

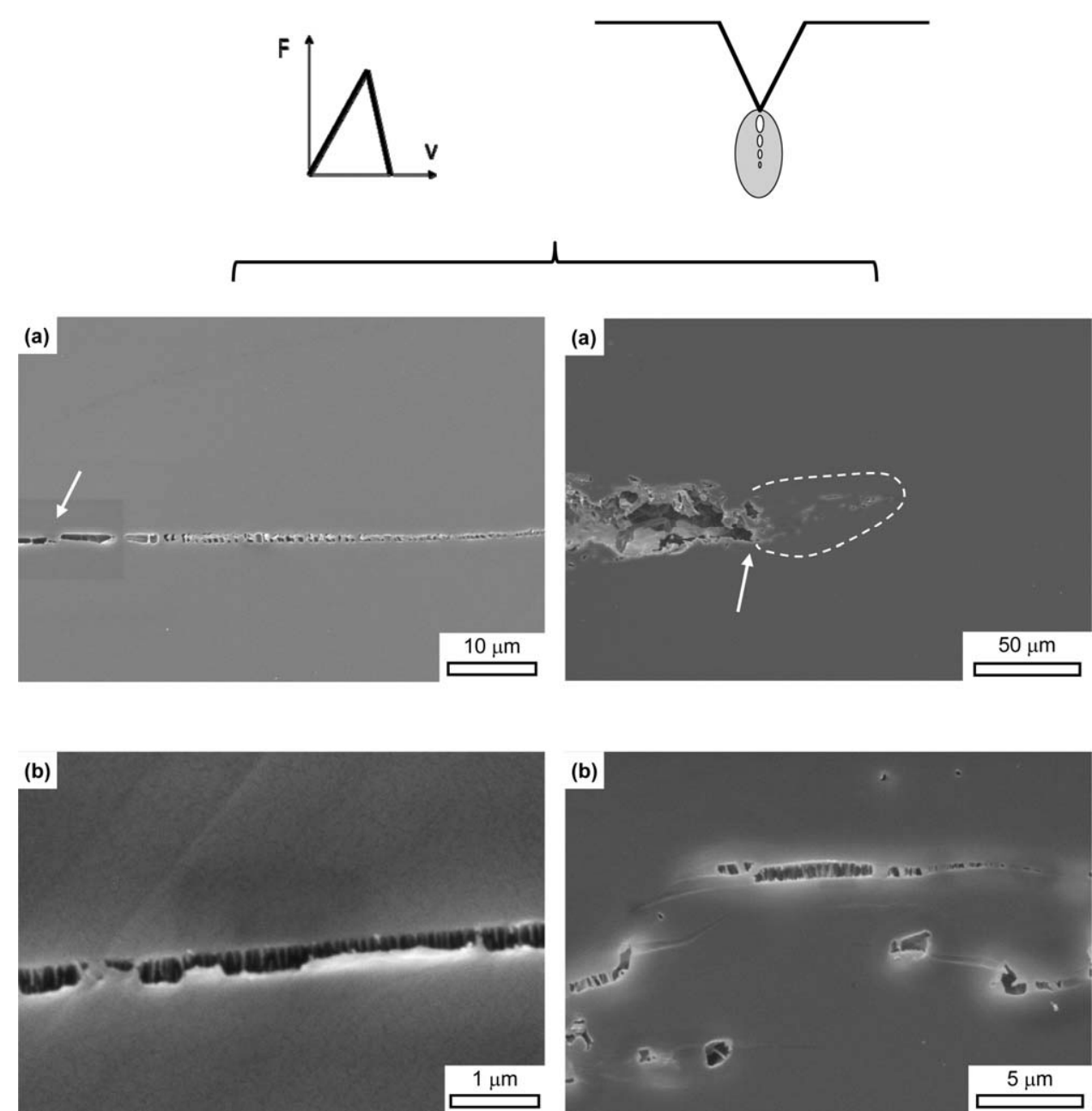

Figure 13. Diagram of the damage appearing in the specimens with no pop-in in the load-displacement diagrams, including Figures 11 and 12 , which are related to the crack front of the nontested specimens after notch sharpening via razor tapping and razor broaching. F and $\mathrm{v}$ represent the force and the displacement, respectively. 


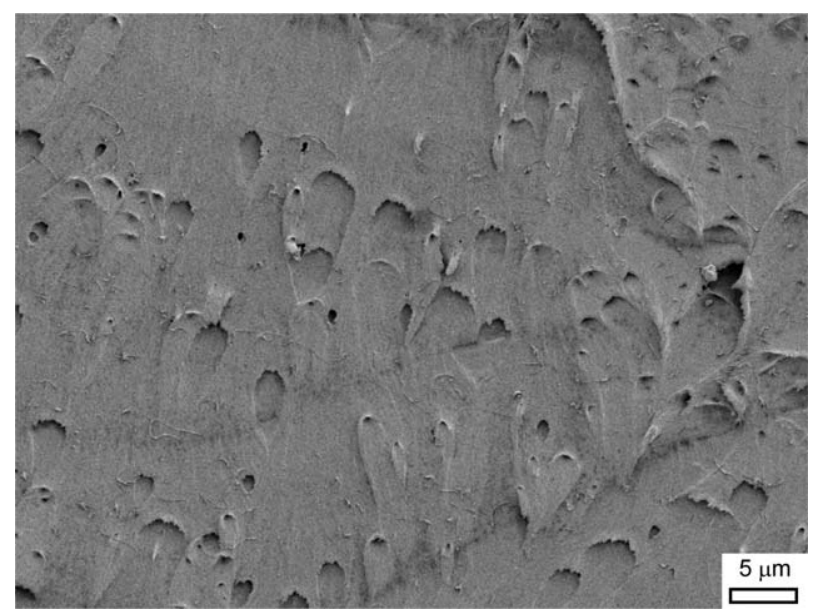

Figure 14. SEM micrograph of the rough surface of the specimen with notches sharpened via razor tapping with no pop-in in the load-displacement diagram. 


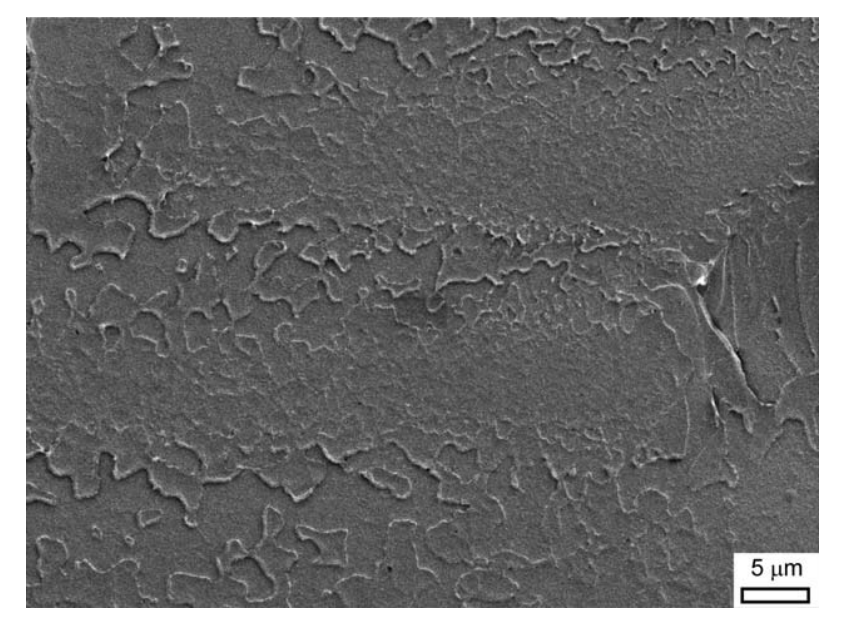

Figure 15. SEM micrograph of the mirror zone of the sample with notches sharpened via razor sliding with pop-in in the loaddisplacement diagram. 

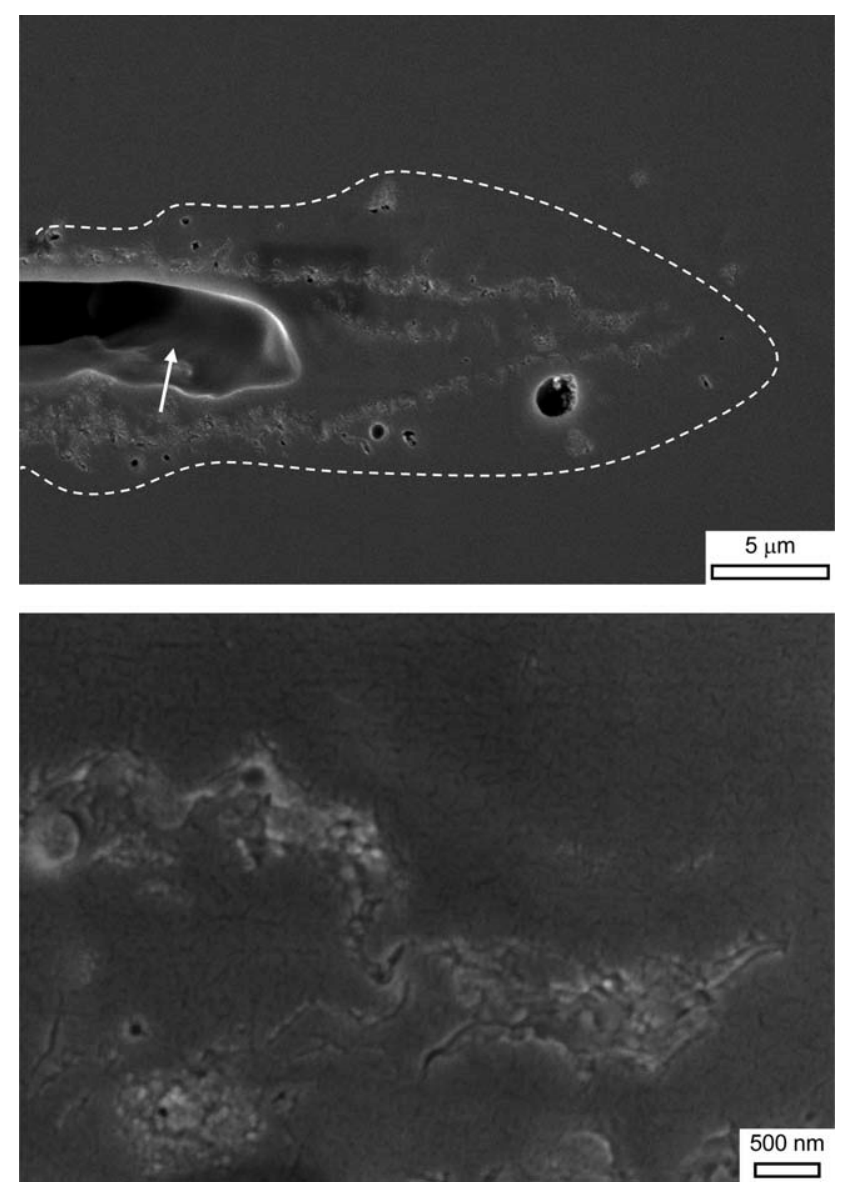

Figure 16. SEM micrographs of the crack front of nontested specimens with notches sharpened via a femtolaser: (a) panoramic view and (b) detail of the damage ahead of the crack tip. The arrow points out the crack tip, and the damaged area beneath the crack tip is outlined with white dotted lines in panel a. 
Table I. Fracture Toughness Obtained from Specimens with Notches Sharpened via Contact Notch-Sharpening Procedures Such as Razor Tapping, Razor Sliding, and Razor Broaching and the Noncontact Femtolaser Procedure in the CCP and URJC Laboratories

Fracture toughness $\left(\mathrm{MPa}-\mathrm{m}^{1 / 2}\right)$

\begin{tabular}{|c|c|c|c|c|c|c|}
\hline \multirow[b]{2}{*}{ Laboratory } & \multicolumn{2}{|c|}{ Tapping } & \multicolumn{2}{|c|}{ Sliding } & \multirow[b]{2}{*}{ Broaching } & \multirow[b]{2}{*}{ Femtolaser } \\
\hline & Pop-in & No pop-in & Pop-in & No pop-in & & \\
\hline CCP & $1.2 \pm 0.2$ & $2.3 \pm 0.3$ & $1.3 \pm 0.2$ & $2.3 \pm 0.2$ & $2.8 \pm 0.2$ & $2.36 \pm 0.04$ \\
\hline URJC & - & $2.6 \pm 0.1$ & - & - & $2.6 \pm 0.6$ & $2.24 \pm 0.04$ \\
\hline
\end{tabular}


Table II. Critical Energy Release Rate Obtained from Specimens with Notches Sharpened via Contact Notch-Sharpening Procedures Such as Razor Tapping, Razor Sliding, and Razor Broaching and the Noncontact Femtolaser Procedure in the CCP and URJC Laboratories

Critical energy release rate $\left(\mathrm{kJ} / \mathrm{m}^{2}\right)$

\begin{tabular}{|c|c|c|c|c|c|c|}
\hline \multirow[b]{3}{*}{ Laboratory } & \multirow{2}{*}{\multicolumn{2}{|c|}{ Tapping }} & \multirow{2}{*}{\multicolumn{2}{|c|}{ Sliding }} & & \\
\hline & & & & & \multirow[b]{2}{*}{ Broaching } & \multirow[b]{2}{*}{ Femtolaser } \\
\hline & Pop-in & No pop-in & Pop-in & No pop-in & & \\
\hline CCP & $0.43 \pm 0.08$ & $1.9 \pm 0.3$ & $0.5 \pm 0.1$ & $1.9 \pm 0.1$ & $2.1 \pm 0.2$ & $1.62 \pm 0.06$ \\
\hline URJC & - & $1.8 \pm 0.2$ & - & - & $1.8 \pm 0.4$ & $1.52 \pm 0.07$ \\
\hline
\end{tabular}


Table III. Crack Tip Radii, Damage Extension ahead of the Crack Tip, and Types of Damage Observed in Virgin SAN Specimens with Notches Sharpened via Razor Tapping, Razor Sliding, Razor Broaching, and a Femtolaser

\begin{tabular}{lllll}
\hline & Tapping & Sliding & Broaching & Femtolaser \\
\hline Cracktip radius $(1 \mathrm{~m})$ & $0.5 \pm 0.1$ & $0.5 \pm 0.1$ & $4.0 \pm 0.5$ & $1.0 \pm 0.3$ \\
Damage extension $(1 \mathrm{~m})$ & $300 \pm 100$ & $300 \pm 100$ & $80 \pm 10$ & $20 \pm 1$ \\
Type of damage & Multiple crazing & Multiple crazing & Multiple crazing & Thermal \\
\hline
\end{tabular}

